\title{
Implementation of an Automatic Side Stand Retractor for Cardinal Motorcycle using Embedded Controller
}

\author{
Md. Fatin Ishraque ${ }^{1}$, Sk. A. Shezan ${ }^{2}$, and Md. Shafiul Islam ${ }^{1}$ \\ ${ }^{1}$ Varendra University \\ ${ }^{2}$ RMIT University
}

May 5, 2020

\begin{abstract}
This paper presents an automatic side stand retractor to ensure the safety of the motorcycle. Many motorcycle accidents take place due to the wrong position of side stand. The automatic side stands retractor prevents the starting of the motorcycle for ensuring safety. The proposed system uses an embedded controller, reed switch sensor, permanent magnet, buzzer and relay. The embedded controller detects the position of side stand using a reed sensor and a permanent magnet attached to it. Then embedded controller breaks the ignition circuit of the motorcycle using a relay in case of the wrong position of the side stand. A buzzer makes a sound to notify the rider to retract the side stand. This system is tested in motorcycle and the obtained result shows the effectiveness of the system for the safety of the motorcycle. The device not only ensure the safety of the driver but also ensure the mobility of the whole system of the motorcycle.
\end{abstract}

\section{Introduction}

The side stand of motorcycle must be kept in proper position while driving. The side stand is kept in a vertical position during driving and is kept in a horizontal position during stand still condition. If the stand is kept in the horizontal position, it can touch the ground while turning the motorcycle in the left. This can lead to serious accident. It is common among the bikers that they often forget to position the stand in the horizontal position.

In our work we have worked on this issue and have designed a protective device using Arduino, Reed sensor and Relay module. The device allows the biker to start the motorcycle only if the motorcycle side stand is in the correct position. Researchers around the world have worked for safety of motorcycles. In [1], a smart motorcycle safety system is designed which has a GPS integrated with it. So, besides motorcycle safety issues, the location of the motorcycle can be tracked.

Using helmet while driving can reduce the effect of an accident [2] and can save lives. That's why researchers have focused on the design of smart and efficient helmets [3-5]. These helmets have many safety features that make motorcycle riding more safe.

In [6], using Bluetooth and smart phones, a vehicle to driver and vehicle to environment communication system is developed to avoid accidents. The vehicles will be able to communicate among themselves while they are in closer distance using Bluetooth. Often it is tough to determine the distance and size of the vehicle behind a rider. In [7], image processing is used for the detection of rear vehicles and to avoid collision.

Motorcycle accidents are caused by many reasons. One of them might cause by wrong positioning of the side stand of the motorcycle. The side stand in a motorbike is used to stand the bike while it is not in motion. 
The side stand is in a vertical position at that time. It needs to be retracted in the horizontal position while in motion to avoid collision with the ground while turning. Sometimes a biker may forget to retract the stand to horizonal position while riding and that cause accident. To protect this various ways have been implemented. In [8], a design for the side stand is proposed which automatically retracts the side stand of the motorcycle while it is in motion. In [9], an electromechanical device is designed that warns the driver if the side stand is not in correct position. In [10] a safety switch is designed that will not allow the biker to start the motorcycle unless the side stand is retracted to its safe position. In [11], a device has been designed that ensures that the motorbike does not start if the stand is in the wrong position. The device also warns the rider by turning on a lamp that the stand is in a wrong position. Matteo Corno and Sergio Savaresi implemented a kick detection algorithm and closed-loop control technique for a pirate motorised cycle to make sure the safety of the motorbike due to the unaware right-side working stand in [12].

All of the mentioned ways of protection schemes have their own advantages and disadvantages. In this paper a digital and simplified solution has been presented to protect a motorcycle from an accident caused by the improper positioning of the side stand. It does not allow the bike to start motorcycle if the side stand is in the wrong position. It senses the position of side stand by using a reed sensor- magnet combination and controls the ignition circuit by a relay. The whole process is operated by the Arduino as embedded controller. This system also warns the biker by an alarm sound if the stand is not in the correct position.

The contributions of the paper are as follows:

1. Developed and applied a digital system of automatic side stand retractor which reduces the possibility of accidents caused by wrong position of side stand of motorcycle.

2. The proposed system does not allow the starting of the motorcycle in case of the wrong position of side stand ensuring more safety of the motorcycle rider.

3. The proposed system is a power efficient.

The residue of the paper contains the system architecture of the proposed system in section II. The experimental setup is discussed at section III. Section IV discusses the result of the system.

\section{System Architecture}

This section presents the architecture of the designed device. The system consists of permanent magnet, reed switch sensor, embedded controller, buzzer and relay. The function of the components are as follows:

\section{Permanent Magnet:}

Permanent magnet is used in this work to identify whether the stand is in horizontal position or not. Neodymium magnet is used which is kept attached with the side stand of the motorcycle. This type of magnets are made from an alloy of Neodymium, Iron and Boron. Hence, called as NIB or Neo magnets.

This is the strongest commercially available permanent magnet $[13,14]$. This magnets can be used in electrical machines as they have high energy product. The maximum energy product $(\mathrm{BH})_{\max }$ (which gives a measurement of the produced field) for a permanent magnet can be calculated theoretically as following [15]:

$(\mathrm{BH})_{\max }=\left(4 \pi \mathrm{M}_{\mathrm{s}}\right)^{2} / 4(1)$

Here $M_{s}$ is defined as saturation magnetization.

The magnet used in our work is circular in shape. It has a diameter of $12 \mathrm{~mm}$ and a height of $1 \mathrm{~mm}$. The magnet is attached with the side stand in a convenient position so that it can be detected by the reed sensor when the stand is in the horizontal position. Whenever the stand goes to vertical position, it will not be sensed. The magnet helps to sense the vertical and horizontal position of the side stand in this way. 


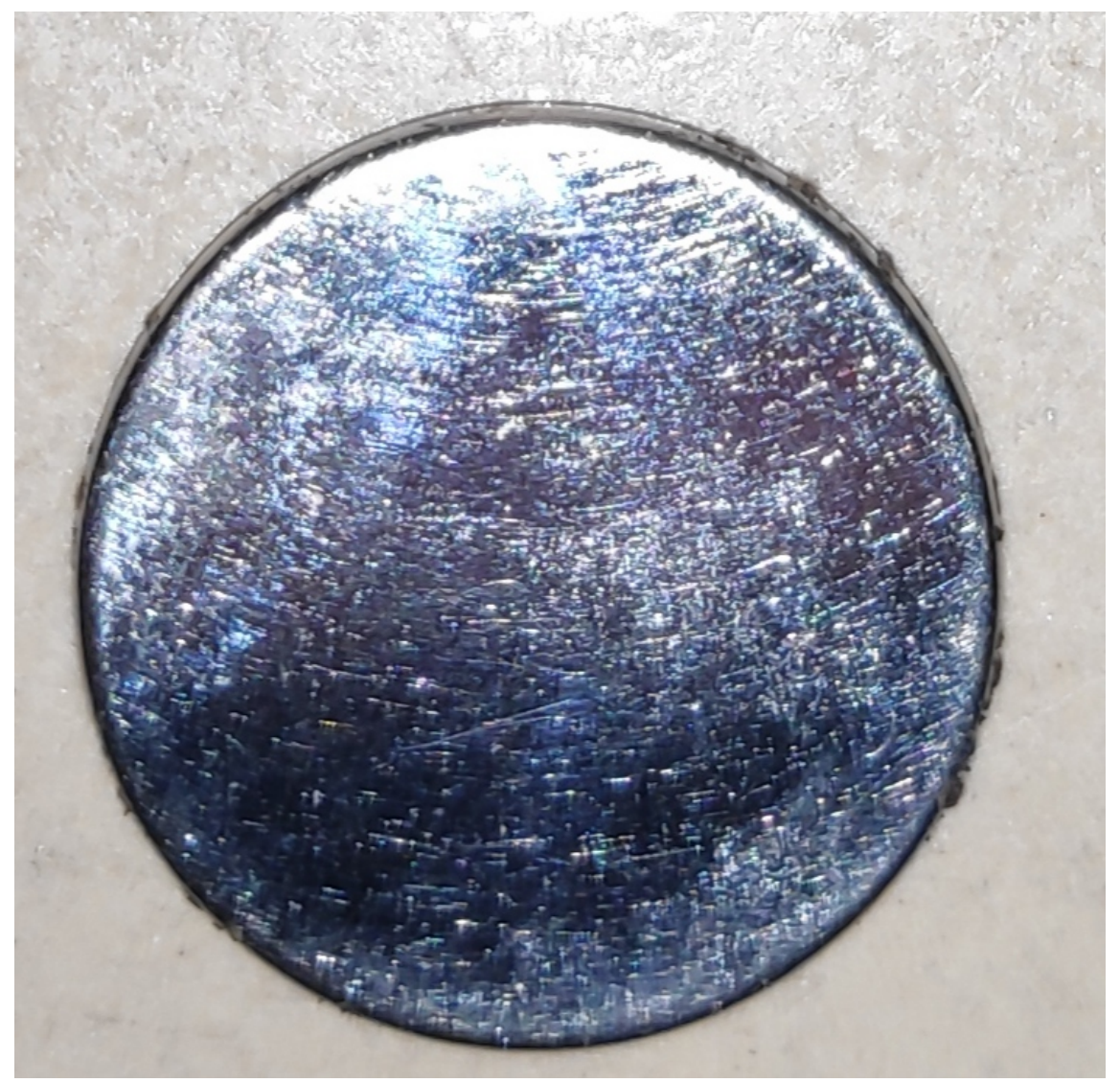

Figure 1: The permanent magnet of the proposed system.

\section{Reed Switch Sensor:}

Reed switch is a magnetically operated electrical switch. Here two ferromagnetic metal 'reeds' which are flexible, are contained in a sealed container or glass tube. In normal condition the two metals don't touch each other that means they keep an open circuit. When a magnetic field is brought closer to the sensor, the contacts touch each other making a short circuit. Removing the field opens the contacts.

Reed switch has use in different types of works. In $[14,16]$ an acceleration sensor is made using it. In [17] a position sensor is made using this. In [18] a proximity sensor is designed using reed switch. In this work reed sensor is used to find the position of the side stand of a motorcycle whether it is in the horizontal position or not. In Fig.2 reed switch sensor of the proposed system is shown. Fig.3 shows complete control unit with the embedded controller and relay. 


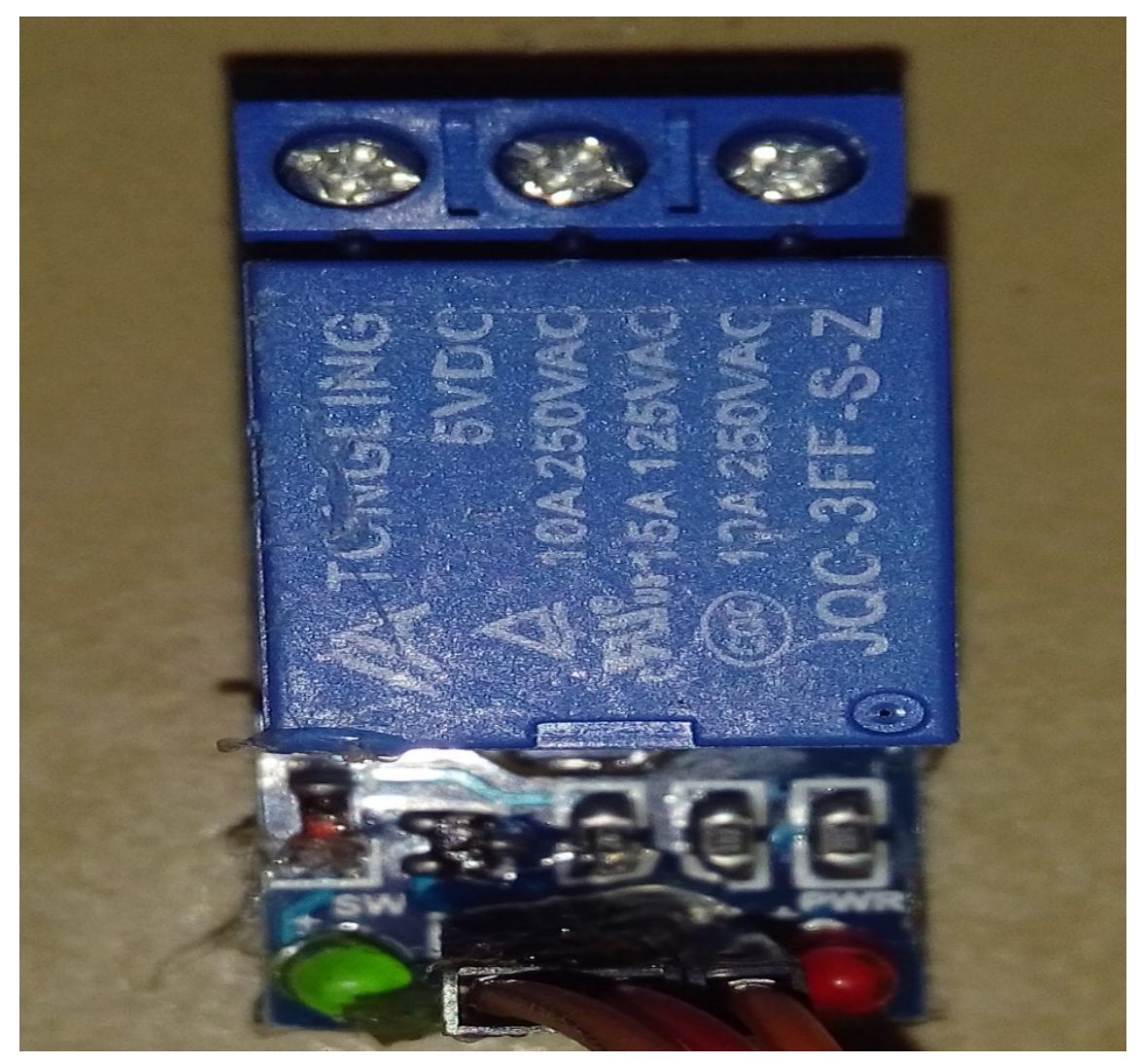

Figure 2: The reed switch sensor of the proposed system.

\section{Embedded Controller:}

Embedded controller is a programmable device based on a microcontroller ATmega 328P. In this work Arduino UNO has been used as embedded controller. This is the brain of the protection system i. It determines the position of the side stand using reed sensor. According to the position, it either does nothing or it operates both the relay and buzzer to open the ignition circuit and warn the rider respectively $[9,18]$. 


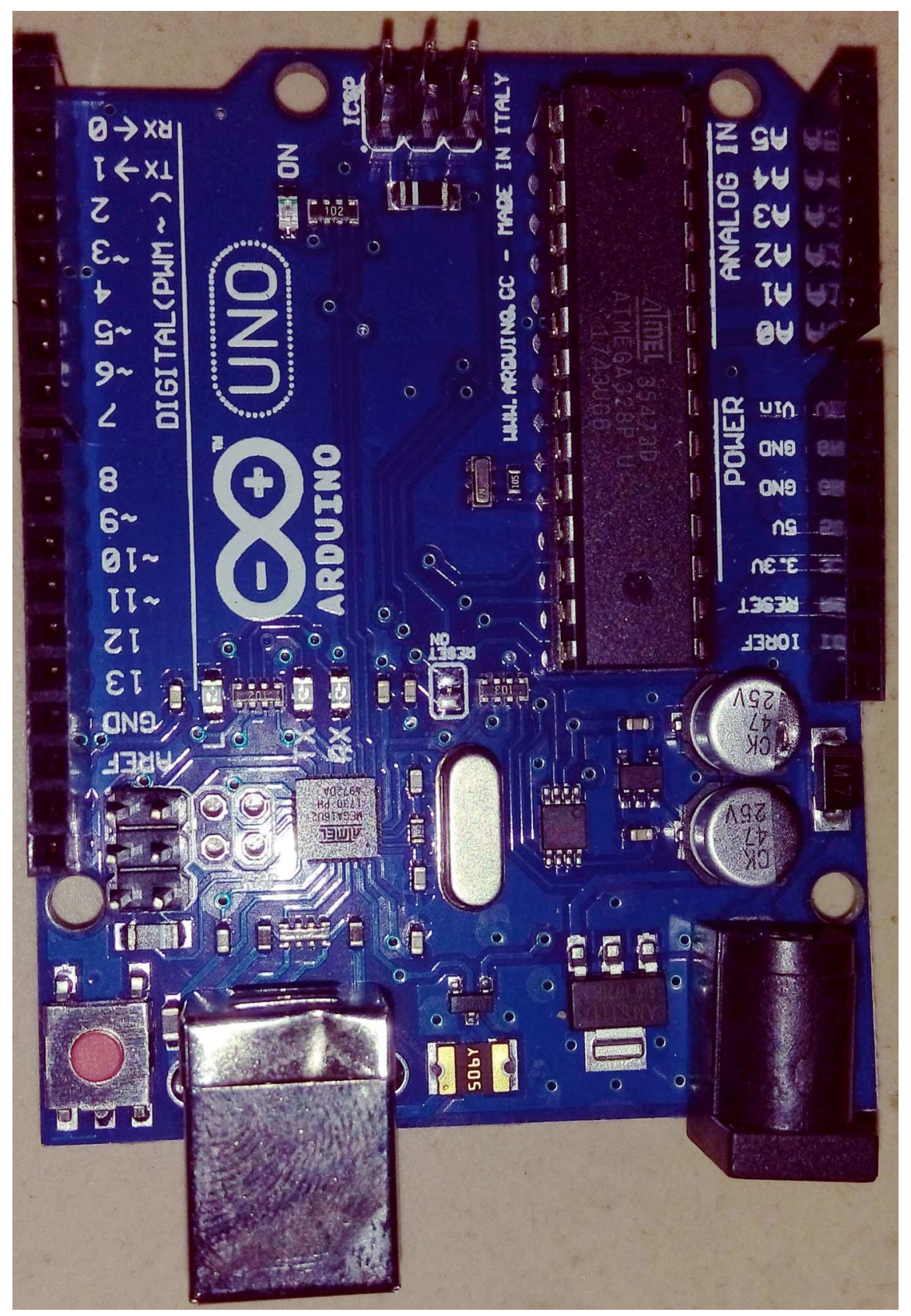

Figure 3: The complete control unit with the embedded controller and relay.

\section{Buzzer:}

A 5V DC Buzzer has been used to warn the driver about the wrong positioning of the stand. The buzzer is operated by the Arduino when a rider tries to turn on the engine of the bike keeping the side stand in the wrong or vertical position [19].Fig.4 shows the buzzer attached with a motorbike.

Fig. 5 shows the Block Diagram of Proposed Control Technique for the Automatic Side Stand Reactor. 


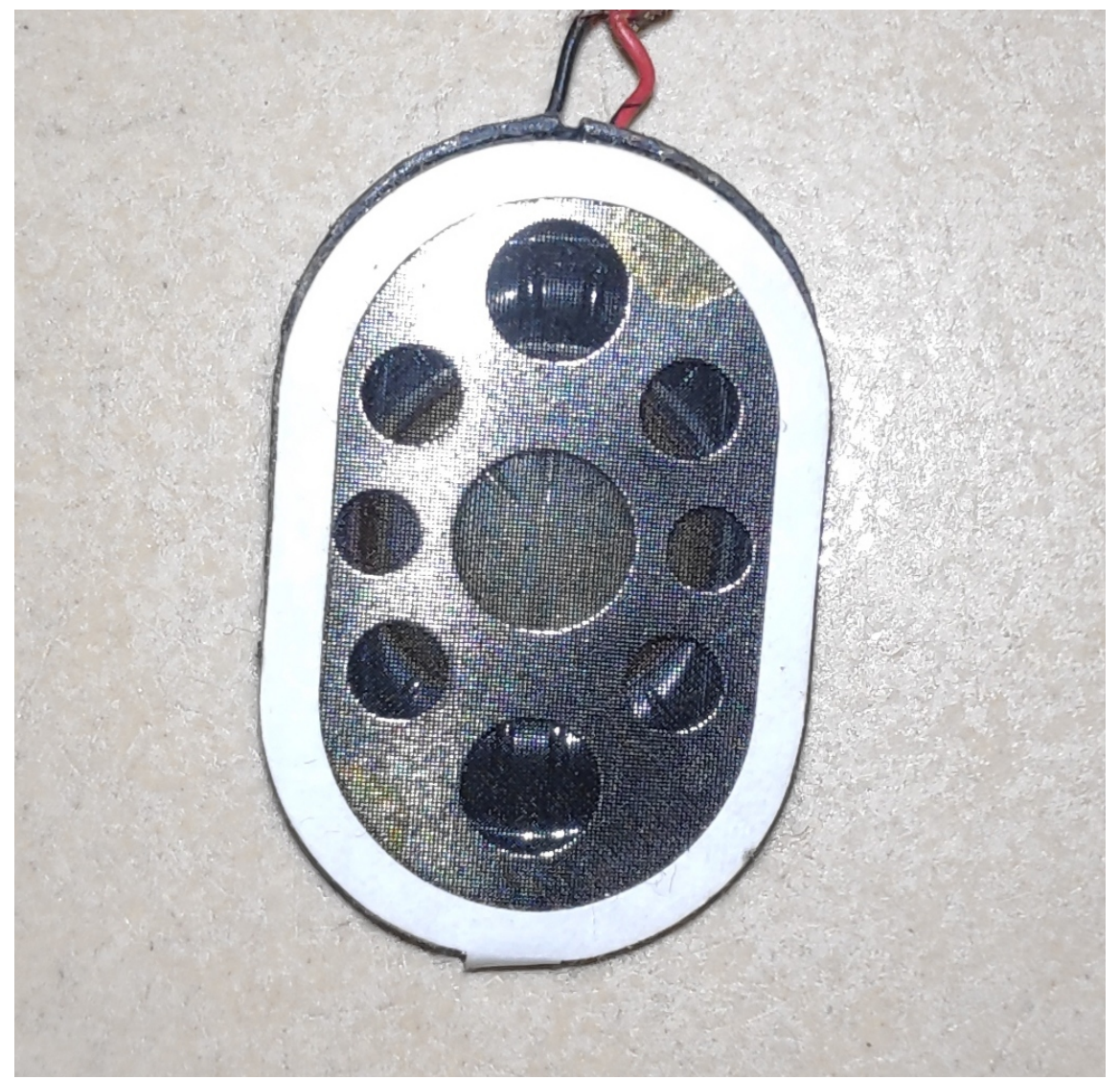

Figure 4: The buzzer of the proposed system.

\section{Relay:}

A relay is used in our work. This relay is operated by the Embedded Controller. This relay comes along with a Circuit breaker. This breaker is connected to the ignition circuit in series. The relay is chosen in such a way that the circuit breaker can handle the high voltage of the ignition circuit. This relay opens the ignition circuit when someone tries to start the motorcycle with the stand in the wrong position [20].

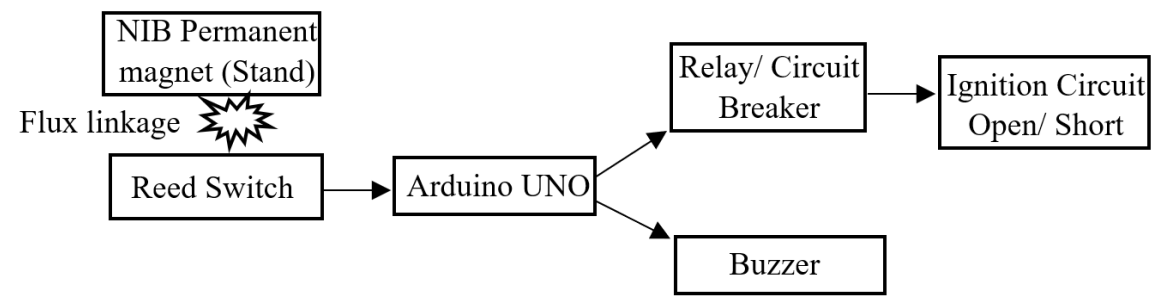

Figure 5: Block Diagram of Proposed Control Technique for the Automatic Side Stand Reactor. 


\section{Experimental Setup}

The device is constructed using the components mentioned above. A simplified block diagram of the device is presented in Fig.1. A NIB permanent magnet is attached to the upper bottom part of the side stand. A reed switch sensor can sense the magnetic field and is placed in a convenient position on the body of the motorcycle. When the stand is in vertical position, the reed switch is out of the region of the magnet and it senses nothing. Whenever the stand is retracted to its horizontal position, the sensor falls inside the field of the NIB magnet. Hence it can sense the magnet.

The reed switch relates to the embedded controller for detection of the side stand position. The logic inside the controller is set in such a way that if the reed sensor senses a field then the stand is in horizontal position. If it doesn't sense magnetic field of NIB magnet then the stand is in the vertical position.

The embedded controller operates a circuit breaker relay and a buzzer after sensing the position of side stand. The circuit breaker is connected in series with the ignition circuit of the motorcycle. When the controller senses that the side stand is in vertical position and the motorbike is powered on, then the controller operates the circuit breaker and opens the ignition circuit. In this condition the bike cannot be started as the ignition coil does not ignite the engine. In addition to opening the ignition circuit, Arduino also operates the buzzer to continuously alert the driver that the stand is not in the correct position.

On the other hand, if the reed switch sensor senses the magnetic field then embedded controller considers that the stand is in horizontal position. In this case the relay does not operate. This means the ignition circuit is closed and the motorcycle can be started. No buzzer is operated in this condition.

This whole protective device is powered from the internal battery power of the motorcycle which is of 12 V DC . This is the recommended power input to an Arduino UNO or embedded controller which can be operated with 5-12 V DC. The whole system only turns on when the bike power supply is turned on using a key. No extra power is lost during the standing condition of the bike when the bike is not turned on with a key.

\section{Result and Discussion}

The device is successfully tested in real life and the device works perfectly. A figure in shown in Fig. 8 where the device is shown connected in a motorbike. The operating time of the relay is fast enough. It is seen that if the stand is in the vertical position, then the bike does not start. As soon as the stand is retracted to horizontal position, then the rider is able to start the bike. If the bike starts and runs in road, then if we suddenly intentionally push the stand down (To vertical position) in running condition, instantly the motorcycle turns off and the buzzer sounds (in the middle of a road).

The system is connected with the motorcycle battery and only operates when the motorcycle power supply is turned on with a key. The power consumption by the system is tested in laboratory and the following results are found. Ideally there in no power loss in the reed switch as it is just one type of contact.

When the side stand is in horizontal position:

When the sensor senses that the side stand is in the correct position then there is no power in the relay and buzzer unit. Only embedded controller itself draws power. Table I and II shows the power drawn in proper and wrong position during the ignition and normal stands.

Table I: Power Drawn When in Proper Position

\begin{tabular}{lllll}
\hline Sl. No. & Components & Current Drawn & Voltage & Power Drawn \\
\hline 1. & Arduino & $26 \mathrm{~mA}$ & $12 \mathrm{~V}$ & $0.312 \mathrm{~W}$ \\
2. & Buzzer & $29 \mathrm{~mA}$ & $5 \mathrm{~V}$ & $0.145 \mathrm{~W}$
\end{tabular}




\begin{tabular}{lllll}
\hline Sl. No. & Components & Current Drawn & Voltage & Power Drawn \\
\hline 3. & Relay Module & $98 \mathrm{~mA}$ & $5 \mathrm{~V}$ & $0.49 \mathrm{~W}$ \\
Total Power Drawn & Total Power Drawn & Total Power Drawn & Total Power Drawn & $0.947 \mathrm{~W}$ \\
\hline
\end{tabular}

When the side stand is in vertical position:

When the side stand is in vertical position embedded controller, buzzer and relay board consume power.

Table II: Power Drawn When in Wrong Position

The operating power of the module is quite low. During test no lag or mismatch was found. The relay operated each and every time while testing.

Fig. 6 shows the flow chart of the proposed system.Fig. 7 shows the proposed side stand retractor. Fig. 8 shows the experimental diagram of the proposed system.

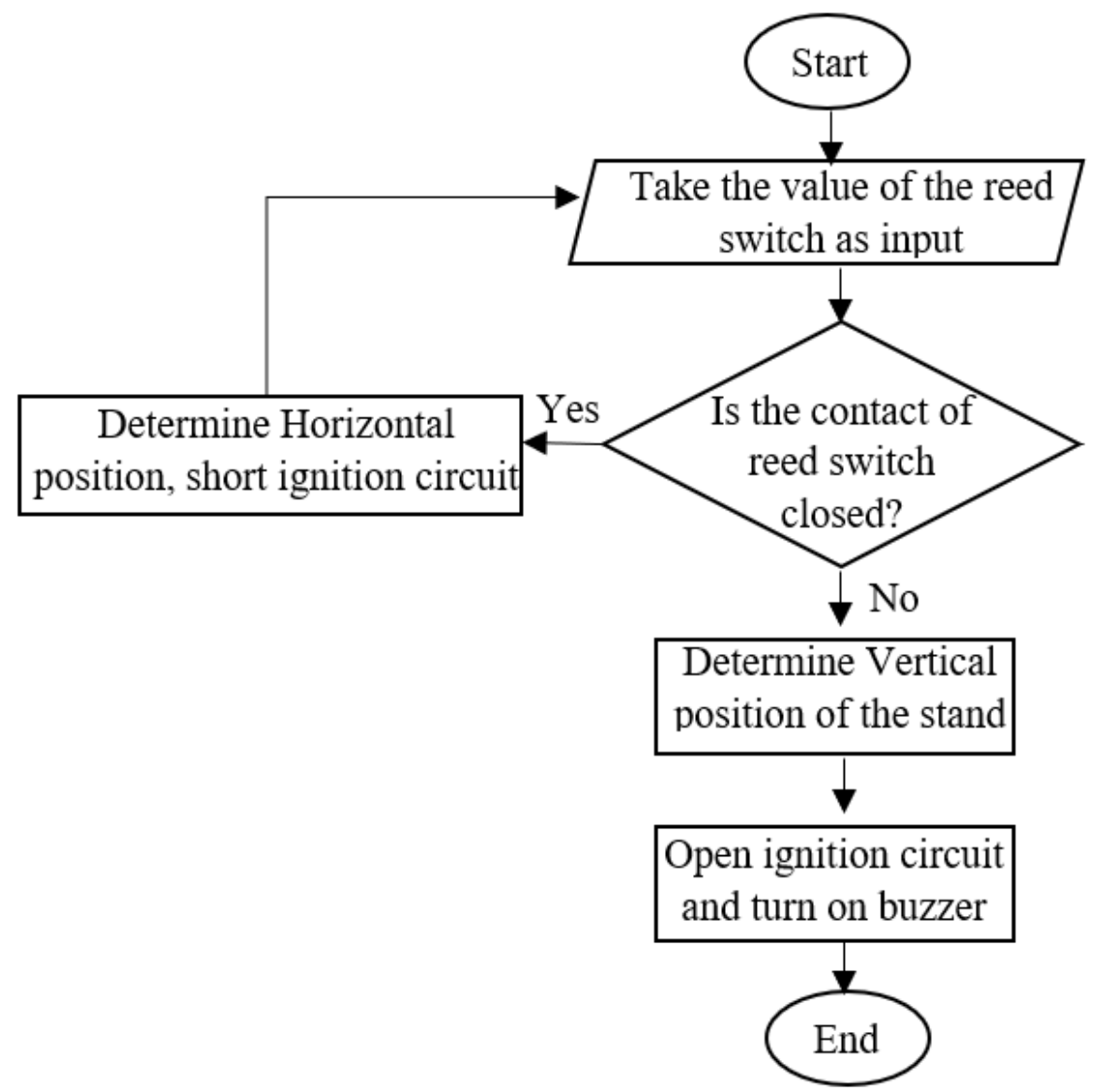

Figure 6: Flow chart of the proposed design. 

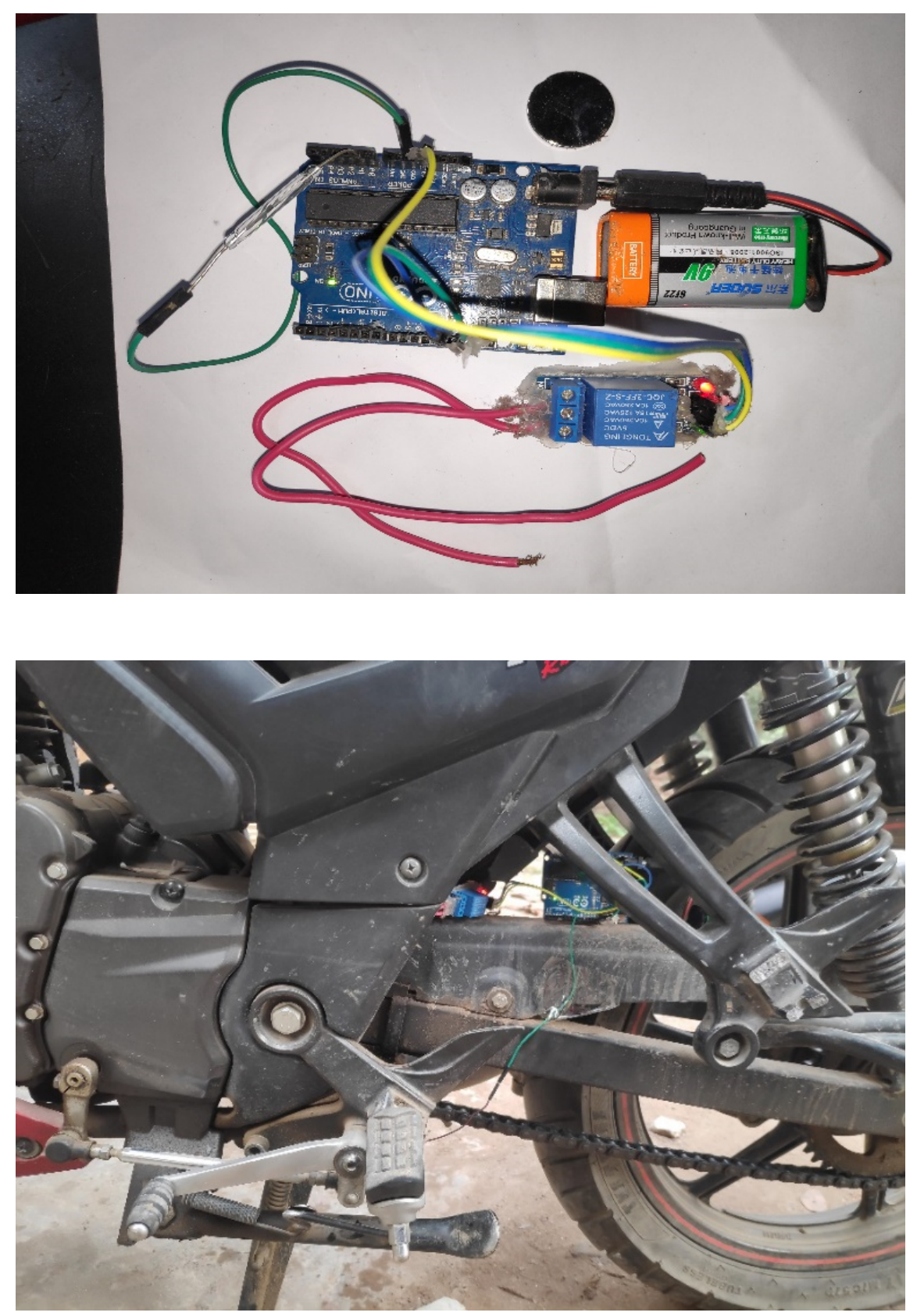

\section{Conclusion}

The amount of bike accidents due to the wrong positioning of the side stand is not negligible. The device designed in this research work can give protection from a bike accident due to the wrong positioning of the side stand. The proposed device is tested with a motorcycle and the obtained results are satisfactory. The designed circuit can readily be marketed for commercial use. This device can provide safety to a biker from an accident with a very low cost and a very negligible power consumption as mentioned above. The working principle of this device is very much user friendly. It is easy to install with a motorbike. This device can protect the rider from an obvious accident due a mistake. 
Acknowledgment: This research work has been completed by the self-funded sources of the author.

Conflict of Interest disclosure statement: All the authors declaring that they do not have any conflict of interest regarding this research paper.

\section{References}

[1] S. Patil, M. G. Hegde, S. Bhattacharjee, and B. Rajeshwari, "Smart motorcycle security system," in 2016 International Conference on Emerging Trends in Engineering, Technology and Science (ICETETS), 2016, pp. 1-4: IEEE.

[2] L. Li et al., "A study on motor-scooter accidents in China and Germany," in 2013 Fifth International Conference on Measuring Technology and Mechatronics Automation, 2013, pp. 110-113: IEEE.

[3] W.-J. Chang and L.-B. J. I. S. J. Chen, "Design and Implementation of an Intelligent Motorcycle Helmet for Large Vehicle Approach Intimation," vol. 19, no. 10, pp. 3882-3892, 2019.

[4] A. Jesudoss, R. Vybhavi, and B. Anusha, "Design of Smart Helmet for Accident Avoidance," in 2019 International Conference on Communication and Signal Processing (ICCSP), 2019, pp. 0774-0778: IEEE.

[5] C.-Y. Yang, C.-F. Wu, H. Samani, and P.-W. Lien, "Ergonomic design of an active alert helmet," in 2013 1st International Conference on Orange Technologies (ICOT), 2013, pp. 151-154: IEEE.

[6] C. Spelta, V. Manzoni, A. Corti, A. Goggi, and S. M. J. I. E. S. L. Savaresi, "Smartphone-based vehicleto-driver/environment interaction system for motorcycles," vol. 2, no. 2, pp. 39-42, 2010.

[7] S. R. Rupanagudi et al., "A novel video processing based smart helmet for rear vehicle intimation \& collision avoidance," in 2015 International Conference on Computing and Network Communications (CoCoNet), 2015, pp. 799-805: IEEE.

[8] M. V. Andrews, "Automatic motorcycle stand retractor," ed: Google Patents, 1942.

[9] M. Gobbi, G. Mastinu, and G. J. I. J. o. A. T. Previati, "Motorcycle Accidents-A New Head and Neck Safety Device for Riders," vol. 20, no. 1, pp. 25-36, 2019.

[10] R.-W. Henn, "Safety device for motorcycle riders and method for operating a safety device for motorcycle riders," ed: Google Patents, 2017.

[11] J. Yu, C. Liu, and H. J. I. T. o. M. Zhao, "Design and Optimization Procedure of a Mechanical-Offset Complementary-Stator Flux-Reversal Permanent-Magnet Machine," 2019.

[12] A. Walton et al., "The use of hydrogen to separate and recycle neodymium-iron-boron-type magnets from electronic waste," vol. 104, pp. 236-241, 2015.

[13] V. M. Ryaboy and W. Booth, "Instrumented platform for vibration-sensitive equipment," ed: Google Patents, 2015.

[14] A. O. Arkhangelskiy, J. Boot, D. M. Hadden, T. Alexander, D. Venhaus, and H. Haselhuhn, "Safety Device," ed: Google Patents, 2017.

[15] V. Ryaboy and W. Booth, "Instrumented Platform for Vibration-Sensitive Equipment," ed: Google Patents, 2015.

[16] D. Ramraika and S. Madhu, "Device for enhanced safety in using a side stand for parking of two wheeled vehicle," ed: Google Patents, 2016.

[17] D. S. Arms, "Bicycle safety device," ed: Google Patents, 2018.

[18] M. R. Aron, "Quick release mechanism with safety collar apparatus," ed: Google Patents, 2017. 
[19] S. García-Herrero, M. Mariscal, R. Beltrán, J. J. R. Gutiérrez, Reliability, S. I. Theory, and P. P. o. ESREL, "Variables influencing the severity of motorcycle and moped traffic accidents in Spain," vol. 202, 2016.

[20] W.-J. Cheng, "Safety motorcycle stand," ed: Google Patents, 2016. 